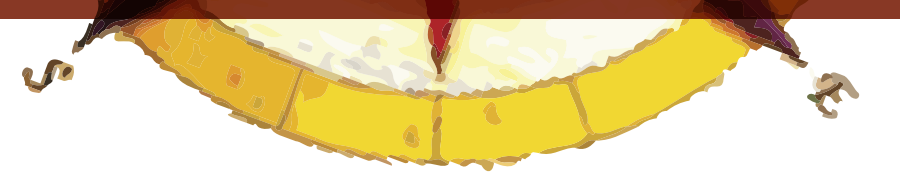

\title{
RAQUEL GUREVICH (COMP.) (2011) AMBIENTE Y EDUCACIÓN. UNA APUESTA AL FUTURO. EDITORIAL PAIDÓS, BUENOS AIRES. ISBN 978 950 12 1534 2. 256 PÁGINAS.
}

\section{LA TEMATICA AMBIENTAL: ENTRE LA POLÍTICA, LA ÉTICA Y EL FUTURO}

La temática ambiental resulta verdaderamente desafiante: por su complejidad, por los actores sociales y económicos que implica, los valores e intereses en juego y las perspectivas de futuro que encierra. Se trata de un objeto de enseñanza que incluye las dimensiones de la política, de la ética, de un modo de estar en el mundo. En efecto, la pérdida de suelos fértiles a expensas del crecimiento de las ciudades, los basureros en el fondo del mar o la extinción de especies son procesos que muestran los modos de vivir, de pensar, de valorar y de consumir de las culturas contemporáneas.

Muchas veces ocurre que estos temas al momento de convertirse en contenidos escolares o en temáticas para ser difundidas a grandes audiencias, se tratan muy superficialmente, de modo naturalizado y sin poner en discusión las fuertes tensiones sociales, éticas, políticas y económicas que conlleva enseñar dichos contenidos. Se requiere de una responsabilidad ciudadana importante para lograr acciones eficaces frente a los problemas ambientales de nuestro tiempo. Cada vez que estos debates circulan en la escuela, estamos colaborando con el ejercicio de prácticas democráticas y proyectos colectivos que refieren a los conflictos que afectan las condiciones sociales y ambientales de las distintas comunidades.

En el libro "Ambiente y educación. Una apuesta al futuro" se presenta al ambiente como aquel conjunto que articula dos grandes sistemas de elementos y relaciones: uno, el sistema natural y el otro, el sistema social. Por ende, atañe aspectos correspondientes a la sociedad, la cultura, la economía y también al campo de las dinámicas físicas, químicas, biológicas, entre otras. En términos educativos, seleccionamos situaciones de enseñanza que pongan en relación dichos elementos, por ejemplo: el sobreconsumo de agua, la deforestación, la minería a cielo abierto. En todos estos contenidos-problemas, las tareas de informar, concientizar y hacerse responsable se tornan imprescindibles para alcanzar la sustentabilidad ambiental en el tiempo.

A lo largo del texto se transitan los principales interrogantes y enfoques relativos a diversos aspectos vinculados con estos problemas y dilemas. Detengámonos ahora en los aportes específicos de los autores. "La cuestión ambiental y sus derivas educativas" y "Propuestas de enseñanza sobre temas ambientales" -a cargo de la compiladora- abren y cierran el libro, presentando un conjunto de criterios significativos para la selección de temas y propuestas de enseñanza sobre contenidos ambientales. Hortensia Castro, autora de "¿A qué nos referimos cuando hablamos de la naturaleza y el 
ambiente. Una exploración a través de ideas y contextos" reflexiona acerca de los sentidos y significaciones de los conceptos naturaleza y ambiente a través de diversas perspectivas de análisis, concebidas en momentos históricos determinados. Lía Bachmann en "Problemas ambientales, manejo de recursos naturales y servicios ambientales: complejidad ecológica y social" se dedica a analizar los conceptos de recursos naturales y servicios ambientales, su valoración económica y cultural; aborda distintas formas de manejo de recursos (explotacionista, integrado y sostenible) y detalla los efectos del manejo explotacionista en los ecosistemas y en las sociedades contemporáneas. Por su parte, "Consecuencias ambientales de la actividad humana: impactos y desafíos futuros", a cargo de Carlos Reboratti, plantea un recorrido por los elementos clave de la "cuestión ambiental", buscando ejemplificar los temas en diferentes escalas de análisis, incluyendo la mención de la situación en América Latina y la Argentina. Silvia González, en "Hacia una gestión integral de los riesgos de desastre" nos propone un esquema teórico-metodológico para comprender y explicar los procesos de planificación y gestión del territorio y del ambiente. Profundiza en las nociones de gestión territorial y gestión de riesgos desde una perspectiva social, especificando las dimensiones del riesgo y las condiciones de una intervención integral sobre los riesgos. Analía Almirón, autora de "Naturaleza, patrimonio natural y turismo. La valorización patrimonial y turística de las cualidades naturales de los lugares" desarrolla la idea acerca de cómo diversas cualidades naturales de los lugares vienen crecientemente formando parte de procesos de patrimonialización orientados a su protección y conservación. También aborda el tema de la naturaleza como bien de consumo turístico, los procesos de invención y construcción social de la práctica turística y el impacto del patrimonio natural como atractivo turístico. Cabe señalar que cada capítulo finaliza con una selección de textos que narran un caso, un ejemplo particular o un testimonio singular para ilustrar aquellas situaciones históricas y perspectivas conceptuales que han sido anteriormente desplegadas.

Podemos decir que el libro en su conjunto concibe la problemática ambiental como una expresión compleja de las relaciones entre sociedad-naturaleza, y que no es posible abordar el tema desde perspectivas individuales y aisladas, o desde enfoques que plantean los problemas ambientales como efectos colaterales o indeseados de las actividades humanas. Por el contrario, se trata de analizar y comprender cómo intervienen el poder y los estilos de desarrollo, la política y los sistemas institucionales en la distribución y apropiación de bienes como el agua, las tierras, la vegetación. Tal esfuerzo educativo nos acerca a un escenario de cooperación colectiva, de una sociabilidad común, de un futuro que habrá que imaginar. El tema ambiental nos recuerda que no hay salvación individual, ni refugios privados frente a situaciones que comprometen la reproducción de las condiciones naturales que hacen posible la vida sobre la Tierra. De allí que podamos plantear que los problemas ambientales y los problemas de la democracia no corresponden a dos campos escindidos uno del otro, sino que se hallan interrelacionados estrechamente entre sí.

Por último, un aspecto referido a la temporalidad. El tema ambiental es un tema del presente y del mañana. Toca la vida y la continuidad de la vida; a nosotros y las generaciones venideras: en definitiva, nos interpela sobre las condiciones de existencia que hemos de ofrecer a las nuevas generaciones para vivir sus vidas, satisfacer sus necesidades y construir sus propios proyectos. Abre preguntas sobre qué es posible renovar, qué es posible crear y qué es necesario conservar. Es evidente la necesidad de construir una agenda social amplia y plural, que incorpore el diálogo entre múltiples actores, saberes y experiencias, para garantizar el acceso a los recursos a los destinatarios futuros de la vida. Como vemos, las temáticas ambientales "no son naturales", y por lo tanto, alentamos propuestas educativas que consideran que los problemas ambientales "son problemas socioambientales". 